environments, for while lnowledge of the geomotry of individual primary particles is valuable, frequently the operative unit is an agglomerate, flocculate or cluster of particles. Often information about what is happening to the constituent particles in an industrial product has to be deduced from the rheological, mechanical or other properties of that product, thero being an inadequacy of methods for directly observing the behaviour of particles within the mass.

In many industrial applications much more information is required about the interplay of particle and particle; about the bohaviour of particles distributed in gas or liquid in various concentrations in relation to the behaviour of single particles in the samo environments; also about the nature of the bond botween such particles and the surrounding mediurn, not only in the static product, but also during the various processes involved in its application or use and subsequent life.

What is the present state of basic knowledge about powders ? Here the conference was greatly assisted by the surveys made in the final section, with their collected information on well-established physico. chemical principles, and on the forces known to operate in dry or wet powders. Careful consideration of such information in relation to particular systoms could, it was suggested, indicate possiblo means of controlling the mochanical behaviour of powders or suspensions.
There woro calls for more information on the fundamentals of powder formation, and of the flow properties, internal packing, etc., of powders ; also on the molecular origin of electrostatic charges, adhesion between particles, and the cohesion of the mass. Thero were indications of the kinds of basic work needed to improve understanding of the factors affecting dispersion and flocculation of particles in solid/liquid systems, involving the inherent surface chemistry of solids, adsorption, chemisorption, etc., and the fine-structure of particles relative to methods (for example, adsorption methods) of measuring 'surface area'. Recent rapid advances in microscopy, and in olectron microscopy in particular, were noted, with the suggestion that microscopists should seek still further to improve their techniques.

To summarize, the symposium brought together a mass of matorial, fundamental and practical. It revealcd the 'zones of ignorance' and the kind of investigations required for' further advance. Individual powder-using industries can be expected to continue the search for new basic knowledge pertinont to the solution of their own problems, but their task would be facilitated by more extensive fundamental studies at the universities and in central research organizations. The field having beon so well surveyod, it would be woll for the participants to meet again in two or three years time to examine progress.

S. H. BELL

\title{
COMPOSITION OF MILK IN THE UNITED KINGDOM
}

$\mathrm{U}$ NTIL quite recently the quality of milk has been judged mainly on its fat content, but in the past thirty years an increased understanding of the principles of nutrition has made it clear that the most important constituents of milk are not the fats but the proteins, minerals and water-soluble vitamins which are, of course, to be found in the non-fatty solids portion of the milk. Research in the past decade has indicated that sinee 1930 or so in England and Wales the content of solids-not-fat: in milk, and therefore the nutritive value of the milk, has tended to decline slightly but significantly. For many hords the solids-not-fat content of the bulked milk has been maintained well above the presumptive legal limit of 8.5 per cent, but for an undesirably high proportion of herds it has frequently been below it.

These facts led in 1958 to the appointment by the Minister of Agriculture, Fisheries and Food, the Minister of Health and the Secretary of Stato for Scotland of an interdepartmental committee under the chairmanship of Dr. J. W. Cook to consider the composition of milk and to recommend any legislative or other changes that might seem desirable. The Committee's report has now been published*. Various members of the Cormmittoo formed three panels, which considered modical and animal husbandry aspects, and the freezing-point (Hortvet) test, for detecting tho presence of added water in milk. The * Milk Composition in the Tinited Kingdom: Report of an Inter-
departmental Committee. Pp. ifi +92. (Cmand. 1147.) (London: $\mathbf{Y} . \mathbf{M}$. Stationcry Ofhce, 1960.) 5s. net. reports of all three panels are published with the main report.

The Committee points out that great progress has been made in past years in improving the hygienic quality of milk; its members rightly believe that similar progress should now be made in improving its nutritive quality. To that end they have put forward some twonty-three main recommendations. They suggest, among other things, that the presumptive minimum legal standard of $8 \cdot 5$ per cont for the solids-not-fat content of milk should be abolished and that price penalties should ultimately be imposed when milk contains $8 \cdot 4$ per cent and less. They recommend also that milk-recording associations should provide means for testing the milk of individual cows for solids-not-fat as well as for fat.

There will certainly be many problems to solve before all the main recommendations made in the report can bo implemented, and some breed societies and other bodies concerned will feel that the recommendations go much too far, while others will inevitably think that they do not go far enough. However that may bo, it is clear that the Committee has done a very thorough job and that the adoption of its recommendations should have the desired effect of arresting and even reversing any tondency thero may be for the nutritional quality of milk in the United Kingdom to decline. The roport contains a wealth of information on the subject of the composition of milk and will long remain a most valuable and reliable work of reference on that subject. 